\title{
BASIC AND ADVANCED SKILLS THEY DON'T HAVE: THE CASE OF POSTGRADUATES AND LITERATURE REVIEW WRITING
}

\author{
${ }^{1}$ Kuang Ching Hei \& ${ }^{2}$ Maya Khemlani David \\ ${ }^{1 \& 2}$ Faculty of Languages \& Linguistic \\ University of Malaya \\ ${ }^{1}$ Corresponding author: kuangch@um.edu.my
}

\begin{abstract}
Purpose - This paper aims to identify the difficulties postgraduate students face in writing the literature review for their thesis and dissertation.

Methodology - Seventy postgraduate students from 9 faculties in one public university in the Klang Valley consented to participating in this study. They were 49 Masters candidates and 21 doctoral (PhD) candidates attending a workshop on academic writing. Among them, 31 were Malaysians and 39 were foreigners with majority being Arabs and Africans. After an icebreaking session, participants were asked what their writing difficulties are when doing their literature review. They were told to write their responses in English in a paper. A linguistic analysis was then applied to the written phrases and expressions which denote their difficulties. These were then categorised under common themes and manually counted in terms of the frequency.
\end{abstract}

Findings - A total of 37 categories of difficulties were detected. They encompassed basic and advanced skills in reading and writing including 'not knowing what to read', 'how to read', 'how to start writing', 'organising', 'doing a critical analysis', 'summarising' and 'synthesising'.

Significance - The findings imply that most of the participants do not possess the necessary skills of reading and writing which are required in most postgraduate programmes. Thus, it is imperative 
that institutions of higher learning develop stricter criteria for student selection. Alternatively, a programme providing support in reading and writing may enable these postgraduate students to raise their level before being admitted. This kind of support can help to mitigate the burden imposed on supervisors as well as develop better quality postgraduate students.

Keywords: Academic writing, challenges, postgraduate students, training.

\section{INTRODUCTION}

Of the many skills a language learner has to learn, writing is the most difficult to acquire because it is a skill that has to be constantly honed through practice as well as through reading. In the world of academia where scholars are encouraged to research and produce publications, good academic writing skills are important. Sometimes viewed as scholarly writing, academic writing skills have to be learnt because it is not just about putting thoughts into words. Academic writing encompasses logic, credibility, conviction, clarity, precision, cohesion and organisation, just to list a few. Academic writing involves creating a text that is not only clear to the reader but is also coherent enough for comprehension. It should comprise good language, is concise, simple to understand and shows respect for the reader such that it does not confuse the reader. Instead, the text and its meaning is clear. A good piece of academic writing should be well supported and should demonstrate a good element of critical thinking.

Postgraduate candidates pursuing higher qualifications have no choice but to produce a tangible thesis or dissertation as a culmination of their tertiary pursuit. This product is then assessed by scholars who are experts in the respective disciplines. Upon reading, the experts would verify two matters: that the research is conducted truthfully, precisely and systematically and that the outcome of the research is documented in the form, format and requirement of a thesis or dissertation. In this regard, specific issues like research problems, methodology, data analysis, discussion and relevant support extracted from previous studies are regarded with care and severity by the examiners. The practice is to ensure that 
the postgraduate candidate fulfills the criteria of being a researcher before he/she is deemed qualified. In some cases, journal articles may also be expected from these candidates. Thus, any postgraduate student registered in a higher learning programme in most institutions in Malaysia must have two basic skills: the competence to read in English and the ability to write in the English language with satisfactory levels. This satisfactory level implies a piece of text that is readable and comprehensible with some level of critical analysis indicated.

In the postgraduate programme, all theses $(\mathrm{PhD})$ and dissertations (masters) must be written according to a certain format but this may differ slightly according to institutions and disciplines. Nonetheless, the chapters contained within these theses and dissertations are more or less the same: Chapter 1 - Introduction, Chapter 2 - Literature Review, Chapter 3 - Methodology, Chapter 4 - Data Analysis and Chapter 5 - Conclusion. Of these chapters, the Literature Review chapter (chapter 2) is of immense importance.

\section{RESEARCH PROBLEM}

The literature review, as a chapter, demonstrates to the examiners or readers, how knowledgeable the candidate is in linking previous studies to current study. The literature review also highlights the competence of the candidate in critically evaluating previous works, providing insights into the gaps or limitations of previous works and to what degree the current study can contribute to knowledge. Although the literature review chapter is an important chapter which exhibits the thinking and writing skills of a candidate, few postgraduate candidates are able to fulfil this requirement satisfactorily. In other words, many postgraduate students have difficulties in developing this chapter and this may be evidenced by the huge turnout of students participating in workshops organised by upskill programmes offered by an established public university (information from the Institute of Graduate Studies (IGS), University of Malaya, June 30, 2015). There are outcomes to the quality of postgraduate students being admitted. For instance, postgraduate students who cannot write academically or are unable to develop a good and coherent literature review suffer because the work they produce for their supervisors 
are criticised. In addition, such kinds of postgraduate students often burden supervisors because supervisors need to spend more time on helping them with the contents of their work. Supervisors supervising weak students become stressed as a result of spending so much time going through their work and correcting their literature review chapter for it to be up to mark. Sometimes, it can cause a conflict and affect the supervisor. Although the problem exists, it appears that many postgraduate programmes offered by public universities in Malaysia do not impose a requirement on their postgraduate candidates to undergo courses such as 'Critical Reading and Writing' (interview with postgraduate students, December 4, 2014). It is deduced that these courses can assist postgraduate candidates to develop the skills they require in their effort to accomplish the writing of a thesis or dissertation. The IGS, University of Malaya, offers upskilling programmes to its postgraduate students. These upskilling programmes expose candidates to quantitative research methods, qualitative research methods, academic writing, literature review writing and critical analysis of journal articles (information gathered from IGS, UM, June 24, 2015).

A quick survey of 58 postgraduate students attending an upskilling workshop on 'Critical Thinking' (IGS, UM, March $3,2015)$ indicates that all had been offered and admitted into the postgraduate programmes based on paper qualifications. Candidates selected for the language faculty, in particular, those from countries where English is a foreign language, were admitted based on their bachelors' degree: Bachelor in Literature Studies, Bachelor in Applied Linguistics or English as a Second Language (ESL), or Bachelor in Translation Studies. It thus seems that offer for admittance was made with the false expectation that candidates already have the minimum proficiency level in English where they possess the competence to read academic works and the advanced ability to write in English.

When the 70 postgraduate participants were asked if they had been assessed on their writing skills, particularly academic writing skills, before they were admitted into the programme, their answers were negative. They also mentioned that they were not interviewed by any personnel in their faculty to evaluate their comprehension skills. Due to this inadequacy, the end result is that majority of the 
postgraduate candidates experience severe difficulties in writing prose, particularly academic writing. This situation seems to occur despite the fact that many had been admitted based on their TOEFL or IELTS scores. Of those who do not possess the relevant scores, a conditional offer is given and they are required to register for a local university English intensive course which they need to pass. Such intensive English courses have components encompassing the four skills of grammar, reading, writing, and speaking. Although these students, whether local or foreign, possess such qualifications in English, few seem capable of writing adequately for their thesis or dissertation. There is no statistic to support this claim but it poses a major problem during supervision (see Fadi, 2010; Fadi, Hillerich, Romero, Topp \& Wnuk, 2010; Kuang, 2013; Sridevi, 2013).

\section{RESEARCH AIM}

This paper examines the difficulties postgraduate students face in writing the literature review for their thesis or dissertation. The findings of this paper will help to convince the administrative division of public universities in Malaysia to provide training in critical reading and writing to postgraduate students as a way of ensuring that they are able to proceed with their postgraduate studies and thereby, be better equipped to complete their postgraduate programmes on time. The information gathered from this paper can enable supervisors to take appropriate measures to empower their own supervisees in academic writing skills consequently, reducing their burden of assisting their supervisees in writing.

\section{LITERATURE REVIEW}

As a chapter, the literature review is a compulsory component in any thesis or dissertation including journal articles. In a thesis or dissertation, the literature review usually comes after the introduction chapter. It is usually written for the benefit of the reader cum examiner who will assess the quality of the candidate's writing and ability to link previous works to his/her current study (Mullins \& Kiley, 2002). Most examiners assess how the student discusses previous works which include critiques and evaluations in the student's own 
voice. Some people consider this a synthesis. The examiners then make an assessment of how original the candidate is in his/her own research by reading for the evidence and reviews of others' works. Occasionally, the literature review chapter enables the examiners to confirm the validity of the research. Besides examiners, other readers focus on the literature review in order to trace the history and progress of a particular research topic. Most often, the literature review serves as the source of credibility.

Bolderston (2008) mentions that the literature review chapter is like the gateway to a research because it informs readers about what is current and past. It provides what is known or unknown, what is controversial and debatable and it serves as an insight into what could be a possible research gap or problem thereby, enabling the formulation of research questions. As is understood, the literature review chapter is a systematic discussion on the progress of a current research which is done by a writer through discussing what has been done, how this is done and in what way it is related to the current study. Since there is no one right way to develop a literature review chapter, many students become confused when they read different theses with different development patterns.

Hofstee (2006) says that a good literature review is a candidate's credential because a well-researched, well organised and well written literature review leaves no room for doubts. He adds that through the selection of the works, the organisation of these reviews, the structure of the focus and the objectivity of the discussion, readers, particularly examiners, can be persuaded to believe the candidate's viewpoints and arguments. However, postgraduate students are not used to selecting a viewpoint and then making an argument out of it because in general, many are not aware of what an argument incurs and how to develop an argument. This inadequacy justifies the necessity to provide workshops on critical thinking, critical reading and critical writing for postgraduate students.

Cooper (1988) says that the literature review is a means of demonstrating an author's knowledge about a particular field of study. This knowledge may include the use of certain vocabulary, theories, key variables and phenomena as well as specific research methods and history. Cooper (1988) suggests that the literature review 
chapter helps students to identify influential researchers and research groups in their selected field of study. In addition, it was noted that a literature review, through some modifications, can also become a "legitimate and publishable scholarly document" (LeCompte, Klinger, Campbell \& Menke, 2003, p. 124). Nonetheless, without some exposure to reading and writing the literature review, it would be extremely difficult for postgraduate candidates, particularly those who are new to writing, to accomplish this requirement. Kuang (2013) mentions that in her experience as a master's candidate in the 1980s in England, she too did not receive such kind of support. She iterates that she too experienced struggles with writing her master's thesis.

Gall, Borg, and Gall (1996) argue that the literature review is extremely important. It can help students to: a) delimit the research problem, b) seek new lines of inquiry, c) avoid fruitless approaches, d) gain methodological insights, e) identify recommendations for further research, and f) seek support for grounded theory. Expanding on this, Hart (1998) says that the literature review should also include the following: a) distinguish what had been done and should have been done, b) identify important variables that are relevant to the topic, c) synthesise and gain a new perspective, d) develop relationships between ideas and practices, e) establish the context of the topic or problem, f) rationalise the significance of the problem, g) enhance and acquire the subject vocabulary to understand the structure of the subject, h) relate ideas and theory to applications, i) identify the main methodologies and research techniques that have been used, and $\mathrm{j}$ ) place the research in a historical context to show familiarity with state-of-the-art developments. All these recommendations further compound the efforts of a postgraduate student as he/she becomes overwhelmed by the importance of the literature review chapter.

\section{Inadequacies of Postgraduate Students}

In a study conducted by Nelson and Amayah (2010), participants mentioned that the most challenging section or chapter to develop is the Literature Review followed by the Research Method, Findings, Conclusion and the Introduction Section. The participants claimed that the literature review is a major problem because they need to 
show that they understand what they had read. They also need to be able to relate their current work to major theories that underpin what they were doing. Many of the participants claimed that they do not have this skill but it was not explained in detail why they lacked the skill. Perhaps it is due to their lack of training or practice.

In looking at the medical faculty, Hutchison (1993) finds that many postgraduate students who were expected to produce a thesis or dissertation lacked the knowledge in writing a good literature review. He mentions that many of the participants in his study were not prepared to deal with knowing what previous research had done and what current research is doing. However, this claim was not supported by any evidence although it may be presumed that the participants were not prepared because of their weakness in reading and comprehension that has been accentuated by their language proficiency.

Hutchison (1993) also notes that those who had successfully completed their thesis or dissertation could have done so through modeling other peoples' work. This is likely to be the main reason because most postgraduate students are not really taught how to write a thesis or dissertation so what better strategy to do this other than to 'model' another person's work or style. This biasness is further exaggerated when Hutchison (1993) asserts that of the many who had already completed their postgraduate degrees, many do not even know how to synthesise, a claim which needs to be justified and substantiated with tangible evidence.

Focussing on how participants reviewed articles, Sargeant, Rajic, O'Connor and Williams (2006) note that the methodological quality discussed by many candidates even on the same topic could vary immensely. They claim that many of the reviews had different conclusions even though summarising skills should have been one of the facets of doing an article review. The authors focus on 65 written articles which were published between the years 2000 and 2005. They note that these articles had addressed the effectiveness of microbial food safety interventions through the criteria used to measure methodological soundness in the medical field. Consequently, the authors conclude that the reviews were poorly done, noting that none of these reviews was able to provide any 
information on the method of locating primary research studies or the inclusion/exclusion criteria for selecting primary studies. The authors further add that none of the reviews had included a critical appraisal of the methodological quality while less than half of the reviews had stated a focused research question, explored possible reasons for the differences in the results of primary studies, discussed the generalizability of results, or even proposed directions for future research. They attribute these inadequacies to the poor reviewing skills of their participants. These claims made by the authors are plausible for they highlight the weaknesses of postgraduate candidates in either reading or writing. However, it appears that no study had ventured into understanding what could be hampering these candidates from being able to complete this task of reading and writing successfully. The findings of the current paper may be able to shed some light in this obscurity.

In another study focussing on candidates' skills in writing the literature review, Smith (1997) studies 25 article reviews and finds that only 14 had provided a clear purpose, with only two revealing the search strategy that had been used to identify the articles for the review. Smith (1997) notes that none had featured any type of quality assessment of the primary studies nor had they stated what criteria were used to determine the assessment, or what material had been included or excluded. Only seven reviews had highlighted useful areas for future research. This finding inevitably led Smith (1997) to conclude that there is little evidence which could show that reviews currently accepted for publication in anaesthesia journals had been prepared systematically. There could be many reasons for this flaw and some of the evidence can be drawn from this paper.

Randolf (2009) says that faulty literature review could be one of the many ways to blemish a dissertation. He further proposes some pivotal information on how to write a high-quality dissertation literature review. He recommends that the literature review should begin with a discussion of the purpose of a review followed by a presentation of the taxonomy of the literature reviews before venturing into a discussion that traces the steps in conducting the quantitative or qualitative literature review. Randolf (2009) also thinks that a framework for self-evaluation of a literature review could be developed for improvement because a flawed literature 
review is a reflection of a flawed dissertation. This opinion is supported by Boote and Beile (2005, p.3) who say, "a researcher cannot perform significant research without first understanding the literature in the field". This again reiterates the need for candidates to have the skill to be able to write a good literature review chapter. Of the many reasons for being unable to write a literature review chapter well, time management could be one. Gall, Borg, and Gall (1996) estimate that the completion of an acceptable dissertation literature review could take anything between three to six months. The authors comment that this is not advisable for postgraduate candidates who are older, hold full time jobs and have families to support because the time taken is considered too long.

Bloom (1982) says that the conflicting demands and problematic priorities that impinge on postgraduate students who are usually selfsupporting can be another reason hampering their pursuit. Matured adults often hold full time jobs and are expected to contribute to the support of a spouse and children and these demands can impact on their time and energy (Bloom, 1982). Some may even be active in community activities which indirectly diminish their focus and ability to write. However, whether or not such time consuming commitments increase their anxiety or are a diversion from it, is still to be substantiated. Bloom (1982) adds that sometimes indirect troubles such as spouses who are not enrolled in studies can distract their partners from writing. Women married to men not likely to obtain an equivalent or superior education may end up with husbands who manipulate their wives either implicitly or explicitly thereby, sabotaging their wives' writing-in-progress schedules. Occasionally, these demanding husbands may become selfish and demand that their wives abide by their rules such as being home by a certain time to prepare dinner. In contrast, men graduate students have more supportive spouses (Bloom, 1982).

Focussing on how Arabs write, Fadi (2010) studies 10 Arab postgraduate students who were registered in the business programme of a public university, Universiti Utara Malaysia (UUM). The sampling comprised five Jordanians, two Iraqis, two Libyans and one Yemeni. All had sat and passed the English Placement Test. Assessing their English writing skills via several academic tasks (project papers, article reviews, summaries, reports, article critiques, proposals, comparative analyses, reviews, analyses 
and essays) Fadi (2010) concludes that these business postgraduate students have difficulties with vocabulary, grammar, organisation of ideas, spelling and referencing.

Mudhovozi, Manganye and Mashamba (2013) focus on the mentors or supervisors. Their participants commented that their own mentees or supervisees lack "expressive skills" (Mudhovozi, Manganye, \& Mashamba, 2013, p. 298). It was further noted that the mentees' or supervisees' proficiency was poor and this further impeded their ability to understand other scholar's work. Other weaknesses identified encompass: poor ability to "put ideas together", cannot "organise their writing", unable to "come up with sub-headings, especially in their literature review", "cannot express themselves", inadequacy in "conceptualising ideas" and in "presenting arguments logically". The mentors also mentioned that their mentees or supervisees lacked "scholarly writing skills" elaborating that their mentees or supervisees also struggled with referencing and citation problems. They complained that these students do not have respect for good language skills because many do not even proof read their work before submitting to their supervisors. Finally, many of their students struggled with the ability to identify relevant literature from the Internet and were constantly referring to outdated sources. All these issues highlighted by the mentors suggest that these are the very skills which a postgraduate student needs to possess in order to be able to produce a piece of acceptable text in academic writing.

\section{METHODOLOGY}

In this paper, 70 postgraduate students (31 locals and 39 foreigners) who were attending a workshop on writing the literature review were asked to write down their responses to the following question: What do you find as the most difficult or challenging aspect of writing the literature review? The participants were in their first and second year of their postgraduate programme with 49 pursuing their Masters degree and 21 pursuing their doctoral degree. They were not preselected but their consent were sought and the aim of the study was explained to them. They were from nine faculties: Arts and Social Science, Built Environment, Business \& Accounting, Computer Science \& Information Technology, Economics \& Administration, Education, Engineering, Languages \& Linguistics 
and Science. All had some level of proficiency in English based on their education and all had English scores denoted by their TOEFL, IELTS and local Intensive English courses. Responses were written in English in prose and point forms. Their personal details were excluded but details like country of origin, faculty and programmes were requested. They were told that the analysis would be used to develop intervention programmes to help them with their writing. Data were then linguistically analysed by focusing on specific phrases or expressions. These were then manually categorized under common themes, counted and tabulated into 37 categories as illustrated below. Based on their frequencies, they were then presented in percentages.

\section{Data Analysis}

Each candidate's written response was first examined for the expressions or phrases. They were then written as statements in columns. Data were then manually written and placed under common themes. Every expression noted from the data was adjusted to fit into the 37 categories for example, 'cannot write smooth' would be placed in the same theme of 'don't know how to write coherently'. Every time the same theme emerges in a response, a tick is indicated in the column to illustrate frequency. This means that one candidate may have more than one difficulty. Data were then divided by 70 and multiplied by 100 to get the percentage. The 37 categories are listed below according to frequency count. Overall, more than half of the participants had the same issues as shown in tables 1 and 2. The percentage tapers as the list increases. The \# sign indicates basic skill and the * sign indicates advanced skill. The list of 37 categories include:

1. *To be able to critically analyse the contents of what I read $(100 \%)$.

2. *To place arguments in support of the research gap (100\%).

3. \#To identify research gaps from my reading (97\%).

4. $\quad *$ To be able to write in a convincing way $(93 \%)$.

5. \#To be able to read the volumes of literature review that I need to read (93\%).

6. \#To be able to start writing the literature review (79\%).

7. *To be able to relate the literature review to my topic of research $(79 \%)$. 
8. \#To be able to detect which reading materials is relevant $(71 \%)$.

9. \#To be able to know which part of the literature review to read and review (70\%).

10. \#Remembering what I have read in the literature review (67\%)

11. \#Don't know where to focus (55.7\%).

12. *Don't know how to write critically (50\%).

13. \#Don't know how to write down ideas (54.3\%).

14. \#Don't know how to connect the ideas (44.3\%).

15. *Don't know how to synthesise $(41.4 \%)$.

16. \#Don't know how to compare what I have read (35.7\%).

17. \#When I read, I cannot understand (35.7\%).

18. \#I have problem with language $(40 \%)$.

19. *Don't know how to review (40\%).

20. *Don't know how to paraphrase (40\%).

21. \#Don't know how to use transitions to show coherence (40\%).

22. \#Don't know how to extract main ideas (35.7\%).

23. \#Don't know how to summarise (28.6\%).

24. \#Don't know how to start a paragraph (27.1).

25. \#Don't know where to start writing (25.7\%).

26. *Don't know how to project argument (21.4\%).

27. \#Don't know how to organise writing (21.45).

28. \#Lack focus looking for materials to read (21.45).

29. \#Don't know when to start writing (20\%).

30. *Don't know when to stop writing (20\%).

31. *Don't know how to write academically (20\%).

32. *Don't know how to give my own voice in the writing $(15.7 \%)$.

33. *Don't know where to limit myself when reading and writing $(14.3 \%)$.

34. *Don't know how to get support for review (7.1\%).

35. *Don't know how to be precise in writing (7.1\%).

36. \#Don't know how to define concepts (4.3\%).

37. *Don't know how to be clear in writing (4.3\%).

\section{DISCUSSION}

As the list above illustrates, more than half of the participants have difficulties in 13 categories with all having the difficulty to analyse critically and to place argument in support of research gap. Three quarters had difficulty in identifying a research gap, writing in a 
convincing manner, speed reading the relevant materials, starting the literature review chapter, relating what is read to topic being researched, reading relevant materials and identifying the relevant components of materials for reading, About half of the participants had difficulty in remembering what was read, focussing, writing critically and writing down ideas.

Since writing involves reading and writing, the difficulties identified were itemised into two tables so as to illustrate the difference between the basic and advanced skills.

Table 1

Basic and Advanced Skills in Reading

\begin{tabular}{|c|c|c|c|c|}
\hline No & Basic Skills & $\%$ & Advanced skills & $\%$ \\
\hline 1. & $\begin{array}{l}\text { \#To be able to identify research } \\
\text { gaps from my reading }(93 \%) \text {. }\end{array}$ & 931 & $\begin{array}{l}\text { 1. } * \text { To be able to } \\
\text { critically analyse the. }\end{array}$ & 100 \\
\hline 2. & $\begin{array}{l}\text { \#To be able to read the volumes of } \\
\text { literature review that I need to read } \\
(93 \%) \text {. }\end{array}$ & 932 & $\begin{array}{l}\text { 2. contents of what I read } \\
\text { *To place arguments in } \\
\text { support of the research }\end{array}$ & 100 \\
\hline 3. & $\begin{array}{l}\text { \#To be able to detect which reading } \\
\text { materials is relevant }(71 \%) \text {. }\end{array}$ & 71 & gap. & \\
\hline 4. & $\begin{array}{l}\text { \#To be able to know which part of } \\
\text { the literature review to read and } \\
\text { review }(70 \%) \text {. }\end{array}$ & 70 & & \\
\hline 5. & $\begin{array}{l}\text { \#Remembering what I have read in } \\
\text { the literature review }(67 \%) \text {. }\end{array}$ & 67 & & \\
\hline 6. & \#Don't know where to focus $(55.7 \%)$ & 55.7 & & \\
\hline 7. & \#I have problem with language & 40 & & \\
\hline 8. & $\begin{array}{l}(40 \%) \\
\text { \#Don't know how to compare what }\end{array}$ & 35.7 & & \\
\hline 9. & $\begin{array}{l}\text { I have read }(35.7 \%) \text {. } \\
\text { \#When I read, I cannot understand }\end{array}$ & 35.7 & & \\
\hline 10. & $\begin{array}{l}(35.7 \%) \text {. } \\
\text { \#Lack focus looking for materials to } \\
\text { read }(21.5) \text {. }\end{array}$ & 21.5 & & \\
\hline
\end{tabular}

From the data shown, it can be noted that most participants experience a lack in basic reading skills while all the participants had problems with advanced reading skills which encompass the difficulty to analyse the works of others critically and to develop arguments to support their research gaps. 
Table 2

Basic and Advanced Skills in Writing

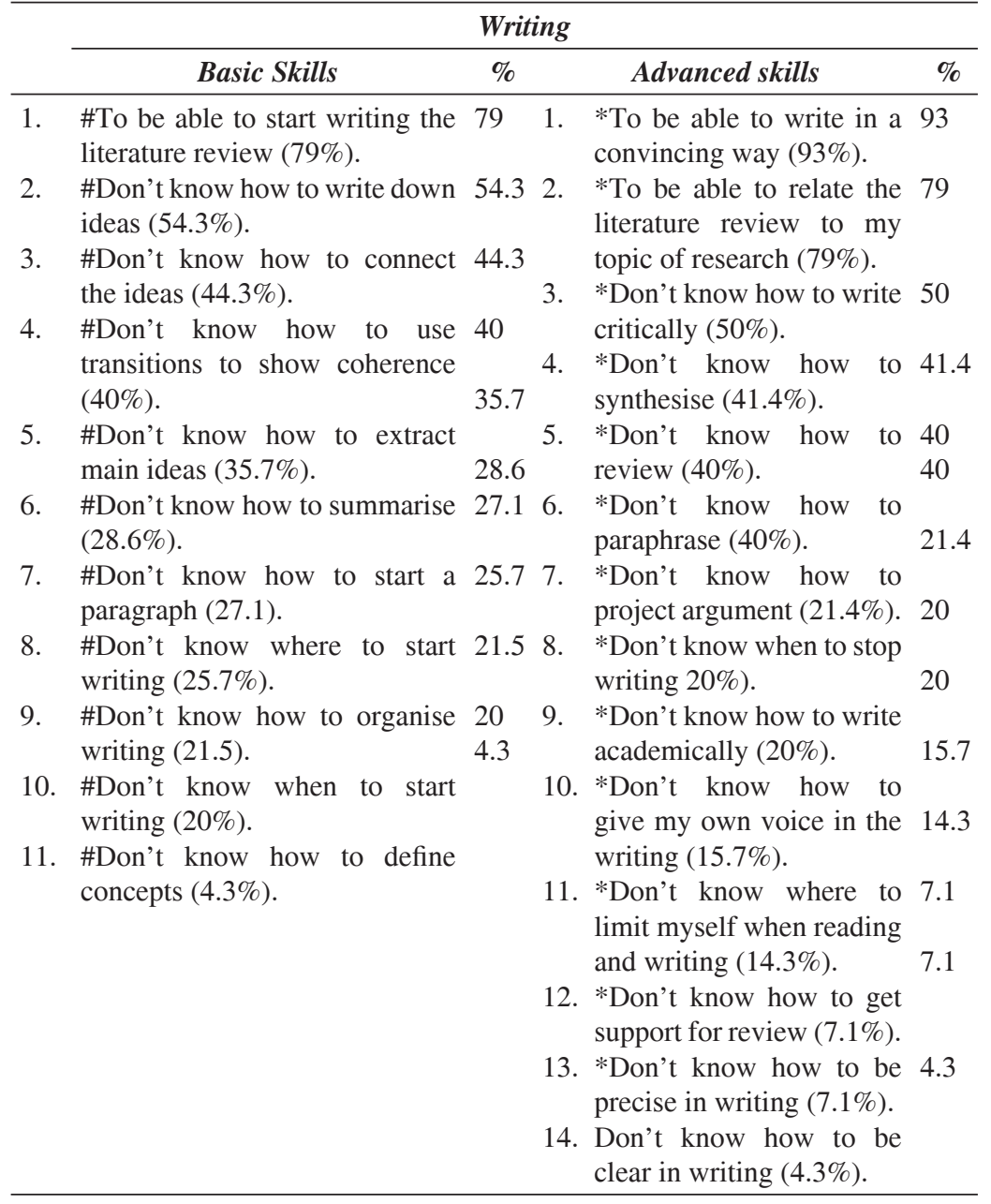

As the data above show, participants have more problems with advanced writing skills than basic writing skills although the disparity is not very wide. The illustrations indicate that majority seem to be hampered by the ability to start writing the literature review chapter, putting ideas down in writing, connecting these ideas and providing coherence in their writing. Clearly, more than a quarter are unable to extract main ideas, summarise ideas, develop adequate paragraphs, while the percentage tapers down to basic 
skills of writing and organising their writing. Less than 5\% claim to be unable to define concepts.

If participants are already lacking the basic writing skills, it is thus, not a surprise if the majority find themselves unable to develop higher writing skills including the ability to be convincing, relating literature to their topic and making a critical assessment of the works read. Less than half of the participants are unable to synthesise, review adequately and to paraphrase while about a quarter are unable to develop arguments, write in an academic manner and place a personal voice in their writing. A small percentage indicates that they do not know how to restrict their writing or even to find evidence to support their review. Only a few indicate being unable to show precision and clarity.

All these issues noted are important and should be addressed as most postgraduate programmes expect candidates to be critical in their writing and capable of supporting ideas and arguments logically. Naturally, if there is no precision and clarity, the writing is also going to suffer (see Bolderston, 2008; Cooper, 1988; Hofstee, 2006). The findings of this paper imply that the quality of the postgraduate students involved in this study is not at par with the requirements of a postgraduate programme. In other words, they have been admitted into a programme that requires them to be able to evaluate and assess what they read so that they can project a critical assessment of the readings and link these to what they hope to unravel and discuss in their study. However, in reality, their competence seems to be below the requirements. Although not all of the participants experienced all the difficulties listed in the 37 categories, it is undeniable that even if a handful of the postgraduate students experience problems with reading and writing, they are definitely going to face more problems with their thesis or dissertation writing. This situation will inadvertently burden their supervisors as well as their own families if their candidature is terminated because of their poor writing skills. Consequently, it can create extreme pressure on the candidates themselves.

It is uncertain what criteria had been used to select these respective candidates but it is obvious that more than half of the participants in this study require help with advanced reading skills as well as 
basic and advanced writing skills. Critical thinking skills seem to be an important element as data in table 2 illustrate, "don't know how to write critically' "don't know how to synthesize" or "don't know how to review", 'don't know how to paraphrase" and "don't know how to write in my own voice" all point to the lack.

\section{CONCLUSION}

The findings of this paper have illustrated one aspect of supervision which shows why many supervisors have problems guiding their supervisees to academic completion. It is no surprise that most of the postgraduate candidates need a lot of support to help them get from where they currently are, that is at the prime of their research work, to the final goalpost of their academic pursuit, that is a worthy thesis or dissertation which is adequate enough to be submitted for examination. This situation may require more support from the Institutes of Graduate Studies in various public institutions which may be able to strengthen the respective programmes by providing intervention skills similar to those of the Upskilling programmes offered by the University of Malaya.

The findings of this study provide evidence to support what the supervisors in Mudhovozi, Manganye and Mashamba's (2013) study had revealed, "supervisees lack many areas of growth" and "expressive skills" (p. 298). The findings of this study also highlight that supervisees' language proficiency is not the only cause of their problem. There are other aspects of their competence such as their skills in reading and writing which can also impact on their academic pursuit. The findings of this study have provided sufficient evidence which indicates that the grievances of most supervisors in supervising weak postgraduate are justified.

The results of this paper show that the postgraduate participants need a lot of help in writing although such support may also come from external organisations that can provide editing and writing services. Nonetheless, it is recommended that institutions of higher learning in this country consider these inadequacies seriously as the impact on supervision is huge and stressful while student graduation time is also affected, not considering that the scholarship of these 
candidates may also affect their future livelihoods. For example, the psychological impact on students upon discovering that they cannot write after having been admitted into a postgraduate programme can be disastrous. As human beings the trauma can affect all forms of relationships and thus, personal lives too.

On the part of the institutions, supervisors too suffer mental anguish when their supervisees are slow in submitting and graduating. Hence, in order to resolve this kind of challenges, institutions of higher learning may want to set a higher criteria for candidate selection or if selection is inevitable, then provide them with a kind of academic support which can help to take them through in their reading and writing skills so that their confidence can be elevated and the quality of the dissertations and theses further improved. This can contribute vastly to internationalisation and globalisation needs.

\section{REFERENCES}

Bloom, L. (1982). Why graduate students can't write: Implications of research on writing anxiety for graduate education. Journal of Advanced Composition, 11(1-2). 1981, 101-117.

Bolderston, A. (2008). Writing an effective literature review. Journal of Medical Imaging and Radiation Sciences, 39 (2), 86-92.

Boote, D. N., \& Beile, P. (2005). Scholars before researchers: On the centrality of the dissertation literature review in research preparation. Educational Researcher, 34(6), 3-15.

Cooper, H. M. (1988). Organizing knowledge syntheses: A taxonomy of literature reviews. Knowledge in Society, 1(1), 104-126.

Fadi Maher saleh Al-Khasawneh. (2010). Writing for academic purposes: Problems faced by Arab postgraduate students of the college of business, UUM. ESP World, 2 (28), Volume 9, 1-23. Retrieved from http://www.esp-world.info

Fadi A., Hillerich, K., Romero, V., Topp, E.A., \& Wnuk, K. (2010). Supervision of a master's thesis: Analysis and guidelines. LTHs 6:e Pedagogiska Inspirations Conferences, 15 December 2010, 1-3. Retrieved from http://www.lth.se/fileadmin/lth/ genombrottet/konferens2010/42_Abdallah_etal.pdf 
Gall, M. D., Borg, W. R., \& Gall, J. P. (1996). Education research: An introduction (6th ed.). White Plains, NY: Longman.

Green, Bart, N. Johnson, Claire and Adams, Alan. (2006). Writing narrative literature review for peer-reviewed journals: Secrets of the trade. Journal of Chiropractice Medicine, 5 (3), 101-117.

Hart, C. (1998). Doing a literature review: Releasing the social science research imagination. London: Sage.

Hofstee, E. (2006). Constructing a good dissertation. Johannesburg: EPE.

Hutchison, B.G. (1993). Critical appraisal of review articles. Family Physician, 39, 1097-1102.

Kuang, C.H. (2013). Introduction. In Kuang, C.H., Raja Maznah R.H., \& Wan Nor Liza W.M. (Eds.), Stories and reflections of student supervision. Kuala Lumpur: ADeC Publications, UM, 11-18.

Kuang, C. H. (2013). Sita My Sita. In Kuang, C. H., Raja Maznah R.H., \& Wan Nor Liza W. M. (Eds.). Stories and reflections of student supervision. Kuala Lumpur: ADeC Publications, UM, 22-28.

LeCompte, M. D., Klinger, J. K., Campbell S. A., \& Menke, D. W. (2003). Editor's Introduction. Review of Educational Research, 73(2), 123-124.

Mudhovozi, P., Manganye, L., \& Mashamba, T. (2013) Mentors' views of supervising post-graduate students undertaking research at an institution in Zimbabwe. Journal of Social Sci, 37(3), 293-300.

Mullins, G., \& Kiley, M. (2002). It's a PhD, not a Nobel Prize: How experienced examiners assess research theses. Studies in Higher Education, 27(4), 369-386.

Nelson, F. and Amayah, A. T. (2010). Conducting a thorough literature review: Is this the most challenging step in the educational research process? Paper presented at the Midwest Research-to Practice Conference in Adult, Continuing, and Community Education, Michigan State University. September 26-28, 2010. Retrieved from https://www.msu.edu/ mwr2p/ NelsonAmayah-MR2P-2010.pdf

Randolf, J. J. (2009). A guide to writing the dissertation literature review. Practical Assessment, Research \& Evaluation, 14 (13), June, 1-13. 
Sargeant, J. M., Torrence, M. E., Rajic, A., O’Connor, A.M., Williams, J. (2006). Methodological quality assessment of review articles evaluating interventions to improve microbial food safety. Foodborne Pathology Disease. 2006, Winter, 3 (4), 447-56.

Smith, A. F. (1997). An analysis of review articles published in four Anaesthesia journals. Canadian Journal of Anaesthesia, 44(4), 405-409.

Sridevi S. (2013). The supervisor as guru. In Kuang, C.H., Raja Maznah R. H., \& Wan Nor Liza W.M. (Eds.), Stories and reflections of student supervision. Kuala Lumpur: ADeC Publications, UM, 99-107.

Interviews with officers from the Institute of Graduate Studies, University of Malaya, June 30, 2015.

Interviews with officers from the Institute of Graduate Studies, University of Malaya, June 24, 2015.

Interviews with postgraduate students in a workshop, Institute of Graduate Studies, University of Malaya, March 3, 2015. Interviews with postgraduate students in a workshop, Institute of Graduate Studies, University of Malaya, December 4, 2014. 